\title{
Biologia reprodutiva de Passiflora capsularis L. e P. pohlii Mast. (Decaloba, Passifloraceae) ${ }^{1}$
}

\author{
Flávia Santos Faria ${ }^{2,3}$ e João Renato Stehmann ${ }^{2}$
}

Recebido em 26/02/2009. Aceito em 11/12/2009

RESUMO - (Biologia reprodutiva de Passiflora capsularis L. e P. pohlii Mast. (Decabola, Passifloraceae)) - O subgênero Decaloba, ao qual pertencem as espécies de Passiflora L. com flores pequenas, é pouco estudado do ponto de vista reprodutivo, o qual pode contribuir para esclarecimento das relações filogenéticas no gênero Passiflora. O objetivo deste trabalho foi estudar a biologia reprodutiva e a polinização de populações de duas espécies desse subgênero, $P$. capsularis e P. pohlii, ocorrentes no estado de Minas Gerais. Determinou-se a receptividade do estigma, viabilidade dos grãos de pólen e a concentração do néctar. Foram realizadas polinizações controladas para verificar o sistema reprodutivo. Foram registrados os visitantes florais e a carga polínica. As flores de ambas as espécies abrem à noite; em $P$. pohlii a antese iniciou-se por volta das $3 \mathrm{~h}$ e a senescência ocorreu por volta das $11 \mathrm{~h}$, já em P. capsularis, a abertura se deu no mesmo horário, mas a senescência ocorreu por volta das $14 \mathrm{~h}$. A concentração do néctar e viabilidade do pólen foram, respectivamente, $34,88 \pm 7,66 \%$ e $80 \pm 0,15 \%$ em P. pohlii e $22,33 \pm 5,82 \%$ e $92 \pm 0,06 \%$ em P. capsularis. Passiflora pohlii é alógama e autoincompatível, enquanto que $P$. capsularis é autógama e autocompatível. Passiflora pohlii teve como polinizadores três espécies de abelhas do gênero Ptiloglossa (Colletidae), enquanto que em P. capsularis os visitantes florais observados foram considerados pilhadores de pólen e néctar. A antese noturna encontrada nas espécies de Passiflora estudadas sugere haver uma relação evolutiva entre espécies de Passiflora subg. Decaloba e himenópteros com hábito noturno, especialmente abelhas do gênero Ptiloglossa.

Palavras-chave: abelhas, antese noturna, biologia floral, polinização, Ptiloglossa

\begin{abstract}
Reproductive biology of Passiflora capsularis L. e P. pohlii Mast. (Decaloba, Passifloracae)) - The subgenus Decaloba (Passifloraceae) is poorly studied on reproductive aspects, which may help our understanding on phylogenetic relationships in the genus. The purpose of this work was to study the reproductive biology and pollination of Passiflora pohlii and P. capsularis, two species belonging to this subgenus with occurrence in Minas Gerais state. Stigma receptivity, pollen viability and nectar concentration were determined. Controlled pollination experiments were done to assess the breeding system. Floral visitors and pollen load were observed. In both species, the flowers start to open during the night. P. pohlii anthesis begins about 3:00 a.m. and its senescence about 11:00 a.m.; the flowers of $P$. capsularis opened about 3:00 a.m. and closed about 2:00 p.m. The concentration of the nectar and viability of the pollen had been, respectively, $34.88 \pm 7.66 \%$ and $80 \pm 0.15 \%$ in P. pohlii and $22.33 \pm 5.82 \%$ and $92 \pm 0.06 \%$ in P. capsularis. Passiflora pohlii was xenogamous and self-incompatible and P. capsularis autogamous and self-compatible. Passiflora pohlii had as pollinators three species of Ptiloglossa (Colletidae) and in P. capsularis all observed visitors were considered nectar and pollen thieves. The nocturnal anthesis showed by studied species of Passiflora suggests an evolutionary relationship among Passiflora subg. Decaloba and hymenoptera, especially Ptiloglossa bees. Key words: bees, floral biology, nocturnal anthesis, pollination, Ptiloglossa
\end{abstract}

\section{Introdução}

A família Passifloraceae compreende 17 gêneros e mais de 600 espécies distribuídas nas regiões tropicais e subtropicais do mundo, cuja maior diversidade é encontrada na região neotropical, onde ocorrem cerca de 500 espécies, grande parte pertencente ao gênero Passiflora (Ulmer \& MacDougal 2004). No Brasil ocorrem três gêneros, Passiflora, Dilkea Mast. e Mitostemma Mast., sendo o primeiro o mais rico, com aproximadamente 130 espécies (Sacco 1980; Cervi 2005). Muitas espécies do gênero Passiflora têm importância econômica pela utilização de seus frutos na alimentação, sua adaptabilidade ao cultivo como planta ornamental ou suas propriedades medicinais (Killip 1938). Várias espécies de Passifloraceae já foram estudadas do ponto de vista reprodutivo (Janzen 1968; Buzato \& Franco 1992; Amela Garcia \& Hoc 1997; Varassin et al. 2001) e diferentes organismos polinizam espécies nessa família, tais como abelhas, vespas, aves e morcegos (Sazima \& Sazima 1978; Endress 1994; Koschnitzke \& Sazima 1997; Varassin et al. 2001; M.F.Acioli, com. pess.).

Apesar das espécies de Passiflora serem facilmente reconhecidas pelas características morfológicas, a sistemá- tica do gênero permanece mal resolvida (Muschner et al. 2003). A taxonomia do grupo foi baseada por muito tempo no arranjo proposto por Killip (1938), que revisando Passifloraceae americanas dividiu o gênero em 22 subgêneros e numerosas seções e séries. Feuillet \& MacDougal (2003) simplificaram a classificação, com base em caracteres morfológicos e ecológicos, dividindo o gênero Passiflora em quatro subgêneros (Astrophea, Decaloba, Passiflora e Deidamioides). Muschner et al. (2003), com base em dados moleculares, reconheceram a existência de três linhagens filogenéticas correspondendo aos três primeiros subgêneros e, recentemente, confirmou-se que Deidamioides é polifilético (V.C. Muschner, dados não public.). Também encontraram que as espécies dos clados correspondendo aos subgêneros Astrophea e Decaloba possuem flores significativamente menores do que aquelas do subgênero Passiflora.

A maioria das espécies de Passiflora estudadas do ponto de vista reprodutivo são pertencentes ao subgênero Passiflora que possui 236 espécies e engloba as espécies com importância econômica (Ulmer \& MacDougal 2004). O subgênero Decaloba que apresenta 214 espécies (Ulmer \&

Parte da Dissertação de Mestrado do primeiro Autor

2 Universidade Federal de Minas Gerais, Instituto de Ciências Biológicas, Departamento de Botânica, Laboratório de Taxonomia Vegetal, Belo Horizonte, MG, Brasil

3 Autor para correspondência: flaviasfaria@yahoo.com.br 
MacDougal 2004), das quais 20 espécies ocorrem no Brasil (Milward-de-Azevedo \& Baumgratz 2004), é um grupo pouco estudado no aspecto reprodutivo. Neste subgênero foram estudadas as espécies $P$. suberosa, polinizada por vespas (Polybia ignobilis Haliday, 1836) e auto-compatível (Koschnitzke \& Sazima 1997; M.F.Acioli, com. pess.) e $P$. misera que é polinizada por abelhas crepusculares do gênero Ptiloglossa (Amela Garcia \& Hoc 1999). Os estudos existentes não permitem caracterizar as estratégias reprodutivas encontradas no subgênero, nem avaliar se a morfologia floral bastante uniforme das espécies deste grupo está associada a polinizadores específicos.

Oito espécies de Passiflora pertencentes ao subgênero Decaloba (sensu Killip 1938) são encontradas na região sudeste do Brasil: P. capsularis, P. misera, P. morifolia, $P$. organensis, $P$. pohlii, $P$. suberosa, $P$. truncata e $P$. tricuspis (Milward-de-Azevedo \& Baumgratz 2004). Dessas espécies, duas são muito comuns na região centro-sul de Minas Gerais, P. capsularis e P. pohlii, sendo que a primeira foi estudada em relação a alguns aspectos de sua biologia floral e sistema de incompatibilidade (Koschnitzke \& Sazima 1997). O objetivo deste trabalho foi descrever a biologia floral, o sistema reprodutivo e a polinização de $P$. capsularis e P. pohlii e verificar se elas são polinizadas por vespas ou abelhas, como já descrito para outras espécies do grupo, a fim de relacionar a morfologia floral às estratégias reprodutivas do subgênero Decaloba.

\section{Material e métodos}

Passiflora capsularis é uma espécie de distribuição disjunta nas Américas e no Brasil ocorre do Pará ao Rio Grande do Sul (Milward-de-Azevedo \& Baumgratz 2004). Foi estudada na Reserva Particular do Patrimônio Natural do Caraça (RPPN - Caraça), no município de Catas Altas, Minas Gerais $\left(20^{\circ} 05^{\prime} \mathrm{S}, 43^{\circ} 29^{\prime} \mathrm{W}\right)$. A RPPN possui uma área de 11.233 ha, com altitudes variando de 800 a $2.072 \mathrm{~m}$. O clima da Serra do Caraça é do tipo Cwb, segundo a classificação de Köppen (Antunes 1986). A população estudada, composta por 15 indivíduos, ocorre nas imediações de edificações. Passiflora pohlii ocorre na Bolívia e em áreas de cerrado no Brasil (Milward-de-Azevedo \& Baumgratz 2004). A população de $P$. pohlii, com 14 indivíduos, foi estudada no município de Belo Horizonte, Minas Gerais $\left(19^{\circ} 52^{\prime} \mathrm{S} 43^{\circ} 57^{\prime} \mathrm{W}\right)$, em remanescentes de cerrados na região da Pampulha. A altitude é de $800 \mathrm{~m}$ e o clima da região é do tipo Cwa (Antunes 1986). O material testemunho de ambas as espécies está depositado no BHCB, sob os números de registro 81675 e 86003.

Forma, tamanho, cor, disposição dos elementos florais e localização do nectário foram registrados em flores frescas ou fixadas em álcool 70\% (n =15). O tamanho e o número de sementes por frutos obtidos em condições naturais $(n=30)$ também foi registrado. A presença de osmóforos foi testada pela coloração com vermelho neutro (Dafni 1992). Dados fenológicos qualitativos (presença e ausência) foram tomados a partir de observações mensais dos eventos reprodutivos nos indivíduos das populações estudadas. Foram registradas as fenofases de botão, flor e fruto.

Para os testes de receptividade do estigma e viabilidade do grão de pólen, dez botões de diferentes indivíduos foram ensacados em pré-antese. A receptividade do estigma foi verificada em campo utilizando permanganato de potássio a $0,25 \%$ (Robinsohn 1924). A viabilidade do grão de pólen foi inferida através do teste indireto de coloração com carmin acético 1,2\% (Radford et al. 1974). A concentração do néctar foi observada a partir de flores $(n=10)$, que foram ensacados em pré-antese. As medidas foram tomadas sempre após a completa abertura das flores, por volta das $6 \mathrm{~h}$. O néctar foi retirado com seringa e a concentração de solutos (açúcares) quantificada através de refratômetro manual. Foram calculados média e desvio-padrão dessas medidas.

Para análise do sistema reprodutivo foram realizados testes de autopolinização espontânea, autopolinização manual e polinização cruzada em seis indivíduos. Em cada tratamento, foram utilizadas no mínimo dez flores, que foram ensacadas no dia anterior à antese. Para autopolinização espontânea, as flores foram ensacadas e não manipuladas. Para autopolinização manual, o pólen foi transferido para o estigma da mesma flor. Para polinização cruzada, grãos de pólen de um indivíduo foram transferidos para o estigma da flor de outro indivíduo. Nesses dois últimos testes, a flores foram re-ensacadas após os cruzamentos. Algumas flores não ensacadas foram marcadas para se observar a produção de frutos em condições naturais.

Para o estudo dos polinizadores foram observados o comportamento dos visitantes florais e o horário e duração das visitas. As duas espécies foram acompanhadas quinzenalmente, sendo as observações em $P$. pohlii realizadas das $5 \mathrm{~h}$ às $11 \mathrm{~h}$ e em $P$. capsularis das $4 \mathrm{~h} 30 \mathrm{~min}$ às $14 \mathrm{~h}$, contabilizando 120 horas de observação para cada espécie. Além de observação direta, fotografias também foram utilizadas.

Os insetos visitantes foram coletados para identificação e depositados na Coleção Entomológica do Instituto de Ciências Biológicas da UFMG. Foram feitas 10 lâminas com gelatina glicerinada (Kearns \& Inouye 1955) para verificar a presença de pólen no corpo dos visitantes florais. Os visitantes florais foram classificados como pilhadores ou polinizadores, de acordo com o comportamento (Dafni 1992). Testes de eficiência do polinizador foram realizados em $P$. pohlii, no qual 15 flores ensacadas em pré-antese foram expostas a uma visita pelo visitante, então, re-ensacadas e acompanhadas até formação de frutos.

\section{Resultados}

Passiflora capsularis - As flores (Fig. 1) têm de 3,2 a 4,2 $\mathrm{cm}$ de diâmetro. As sépalas são lanceoladas, oblongas, esverdeadas e as pétalas são linear-lanceoladas e brancas. A corona apresenta uma única série de filamentos e é branca e reflexa. $\mathrm{O}$ opérculo é membranáceo e plicado. A câmara nectarífera é anular e limitada pelo límen, que é carnoso. $\mathrm{O}$ androginóforo é esverdeado, apresenta base anular e mede da base até os filetes de 0,8 a $0,95 \mathrm{~cm}$. Os filetes e estiletes são brancos e o pólen é pulverulento e branco. O ovário é oblongo e verde. $O$ fruto é capsular, fusiforme e verde-amarelado, se abrindo irregularmente quando maduro. As sementes são elipsóides, sulcadas transversalmente e têm 3,39 $\pm 0,15 \mathrm{~mm}$ de comprimento. O número médio de sementes por fruto foi de $79 \pm 18,86$.

Passiflora capsularis floresceu e frutificou dos meses de setembro a maio, com pico de floração em outubro e novembro. Os botões demoram cerca de 20 dias para completarem seu desenvolvimento e a flor dura um dia. As flores nascem nas axilas foliares, raramente aos pares, neste caso sendo uma mais nova que a outra, o que faz com que não abram ao mesmo tempo. As anteras introrsas sofreram deiscência ainda no botão e os estiletes ficam voltados para o ápice. A antese iniciou por volta das $3 \mathrm{~h}$ e por volta das 5 h30min os estiletes estavam totalmente deflexos. A abertura da flor começou pela base das sépalas (Fig. 2), se estendendo para o ápice, deixando as anteras extrorsas, num rápido movimento. Os estiletes permanecem no ápice e a sua deflexão dura aproximadamente duas horas (Fig. 3). Após esta fase, filetes e estiletes ficam perpendiculares ao androginóforo. Em algumas flores, entretanto, a deflexão das anteras e do estilete não ocorre. As sépalas, pétalas e a corona 
movimentam-se em direção ao pedicelo da flor, tornando-se reflexas (Fig.4). A senescência da flor ocorreu por volta das $15 \mathrm{~h}$, e caracterizou-se pelo fechamento das pétalas, sépalas e corona. Os estiletes retornam à posição inicial do botão floral, enquanto os filetes murcham e descem em direção à base do androginóforo. Os estigmas permaneceram receptivos durante toda a antese. As flores possuem um odor de baunilha que começa a ser exalado ao final da deflexão dos estiletes. O néctar teve concentração de $22,4 \pm 5,94 \%$ ( $\mathrm{n}=$ 10). O pólen apresentou $92 \pm 0,06 \%(\mathrm{n}=10)$ de viabilidade.

A espécie é autocompatível, não havendo diferença na produção de frutos entre polinizações cruzadas, autocruzamentos e flores expostas aos polinizadores $\left(\chi^{2}=6,82, \mathrm{gl}\right.$ $=3, p=0,078)($ Tab. 1). A transferência do próprio pólen para o estigma ocorre durante a abertura da flor, quando ele é encontrado depositado secundariamente nos estiletes e até mesmo pétalas e sépalas. $\mathrm{O}$ crescimento do ovário foi detectado visualmente três dias após a antese e o fruto levou aproximadamente 40 dias para amadurecer e abrir.

Apenas Trigona fulviventris (Guérin 1835) e T. spinipes (Fabricius 1793) foram observadas eventualmente coletando pólen e néctar. As visitas iniciaram por volta das $8 \mathrm{~h}$ e duraram de 10 a 62 segundos. Estas abelhas pousavam sobre a corona e acessavam a câmara nectarífera para tomar o néctar. Quando iam coletar pólen, pousavam diretamente sobre o androginóforo, se direcionando às anteras ou pousavam sobre a corona e subiam o androginóforo em direção às anteras. Em ambas situações, essas abelhas não tocavam os órgãos reprodutivos.

Passiflora pohlii - As flores (Fig. 5) têm 2,5 a 4,5 cm de diâmetro $(\mathrm{n}=10)$. As sépalas são lanceoladas, oblongas e esverdeadas e as pétalas linear-lanceoladas e brancas. A corona é branca e apresenta duas séries de filamentos, a externa maior e a interna menor e paralela ao androginóforo. O opérculo é membranáceo e plicado, com as margens arroxeadas. A câmara nectarífera é anular, limitada pelo límen, que é carnoso. $\mathrm{O}$ androginóforo de cor roxa apresenta base anular e da base até os filetes tem $1,5 \mathrm{~cm}$. O ovário é globoso e verde, os filetes e estiletes são roxos e o estigma é capitado e verde. O pólen é amarelo e pegajoso. O fruto é uma baga globosa púrpura-escuro, com até $2 \mathrm{~cm}$ de diâmetro. As sementes são oblongiformes e sulcadas transversalmente, com 3,46 $\pm 0,25 \mathrm{~mm}$ de comprimento. O número médio de sementes por fruto foi de $24 \pm 14,2$.

Passiflora pohlii floresceu e frutificou o ano todo, com pico de floração em setembro e outubro. Os botões demoram cerca de 20 dias para completarem seu desenvolvimento e as flores duram apenas um dia. As flores ocorrem aos pares nas axilas foliares, sendo uma mais nova que a outra, o que faz com que geralmente não abram ao mesmo tempo. No botão em pré-antese as anteras já sofreram deiscência, com abertura introrsa, enquanto os estiletes estão voltados para o ápice. A antese iniciou durante a noite, por volta das $3 \mathrm{~h}$. A abertura da flor começa pelo ápice das sépalas (Fig. 6) e estende-se para a base, e as pétalas acompanham esse movimento. No momento da abertura, as anteras giram para fora, tornando-se extrorsas num rápido movimento. Os estiletes permanecem no ápice e a sua deflexão dura aproximadamente duas horas (Fig. 7), o que acontece por volta das $5 \mathrm{~h}$. Após esta fase, filetes e estiletes ficam perpendiculares ao androginóforo (Fig. 8). As sépalas e pétalas se movimentam em direção ao pedicelo da flor, se tornando reflexas. A senescência da flor ocorreu por volta das $11 \mathrm{~h}$, e se caracteriza pelo fechamento das pétalas, sépalas e corona. Os estigmas permanecem na mesma posição enquanto os filetes murcham e descem em direção à base do androginóforo. Eles estiveram receptivos desde a abertura da flor até às $9 \mathrm{~h}$. As flores possuem um odor cítrico, que lembra citronela. Este odor começa a ser liberado no final da deflexão dos estiletes, por volta das $5 \mathrm{~h}$ $15 \mathrm{~min}$. O néctar é acumulado debaixo do opérculo, mas em algumas flores, parte se deposita também entre o opérculo e a corona. A concentração de açúcares foi de $34,3 \pm 7,27 \%$ ( $n=$ 10). O pólen apresentou $80 \pm 0,15 \%(\mathrm{n}=10)$ de viabilidade.

A população estudada não foi capaz de se autopolinizar e foi auto-incompatível $\left(\chi^{2}=34,07, g l=4, p<0,001\right)$, pois não produziu frutos nos tratamentos de autopolinização espontânea ou manual (Tab. 1). O teste de emasculação levou ao aborto das flores. No ensaio de eficiência dos polinizadores, houve $80 \%$ de sucesso de produção de frutos $(\mathrm{n}=12)$ após uma única visita pelas abelhas do gênero Ptiloglossa. Três dias após a polinização observou-se o aumento de tamanho do ovário. O fruto levou $c a .40$ dias para amadurecer, tornando-se macio e de cor púrpura escuro. Os únicos animais observados se alimentando dos frutos foram percevejos (Insecta, Hemiptera), que não tem relação com a sua dispersão. Frutos amadurecidos foram removidos das plantas, mas seus consumidores não foram identificados.

Passiflora pohlii teve como visitantes florais as abelhas Apis mellifera (Linnaeus 1758); Trigona spinipes; Plebeia droryana (Friese 1900); Ptiloglossa dubia (Moure 1945); P. latecalcarata (Moure 1945); P. styphlaspis (Moure 1945); a mosca Drosophila melanogaster (Meigen 1830) e formigas do gênero Acromyrmex (Tab. 2). As três abelhas do gênero Ptiloglossa (Fig. 8) visitaram as flores de P. pohlii durante toda a floração. Foram coletados 28 espécimes, destes 24 machos (12 de P. styphlaspis, 11 de P. dubia e um P. latecalcara-

Tabela 1. Polinizações controladas para verificar o sistema reprodutivo em flores de Passiflora capsularis L. na RPPN Santuário do Caraça, Santa Bárbara e Passiflora pohlii Mast. em Belo Horizonte, estado de Minas Gerais, Brasil. Dados representam a razão entre número de frutos e de flores, com o valor percentual entre parênteses.

\begin{tabular}{lcc}
\hline Tratamento & Passiflora capsularis & Passiflora pohlii \\
\hline Polinização cruzada & $7 / 17(41)$ & $26 / 30(86)$ \\
Autopolinização & & \\
- espontânea & $4 / 28(14)$ & $0 / 30(0)$ \\
- manual & $8 / 10(80)$ & $0 / 21(0)$ \\
Emasculação & - & $0 / 10(0)$ \\
Condições naturais & $13 / 45(29)$ & $23 / 40(57,5)$ \\
\hline
\end{tabular}



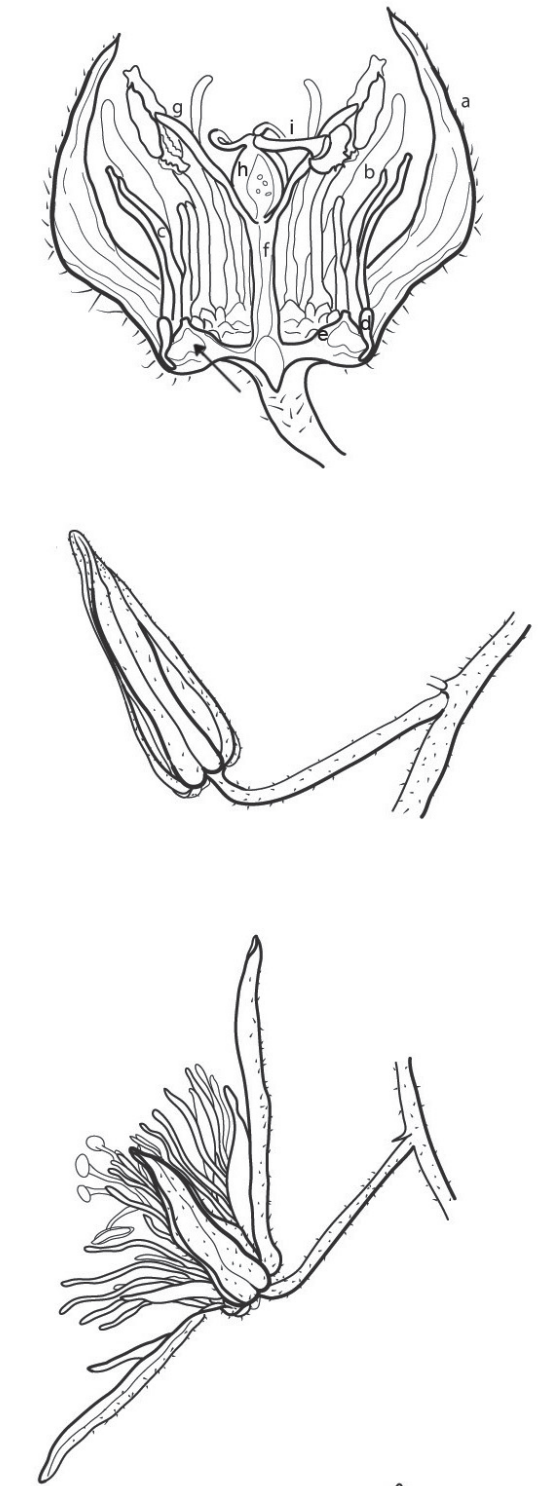

4.

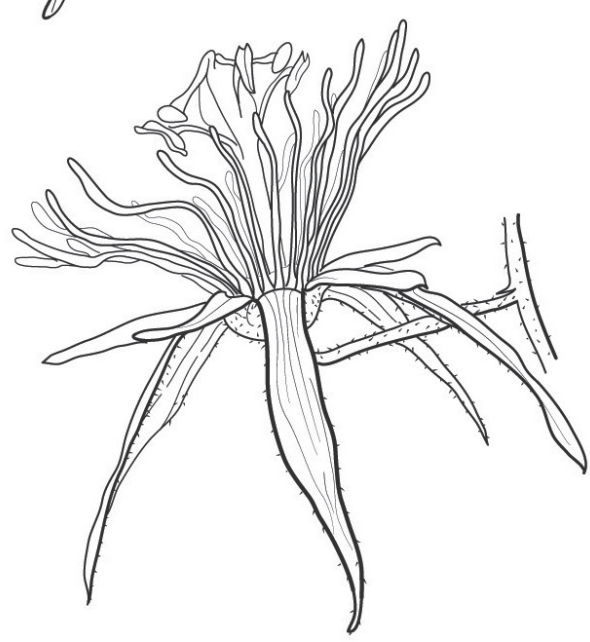

1 .

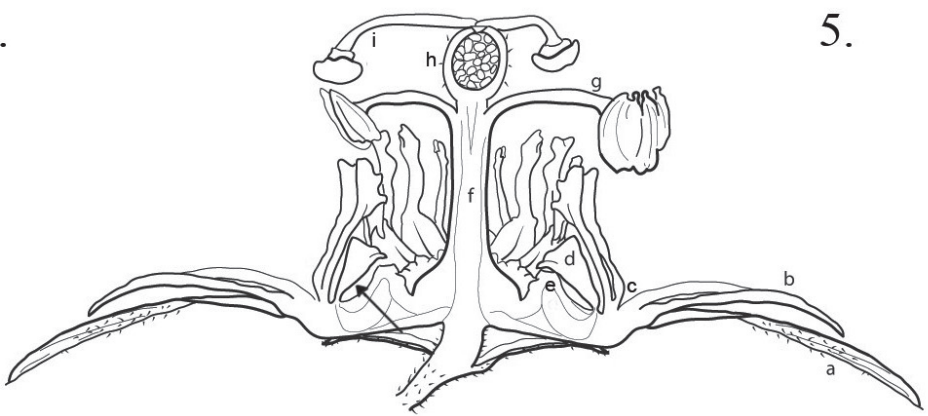

2.

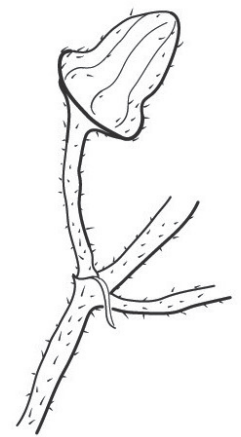

6.
3.

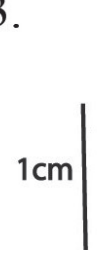

7.

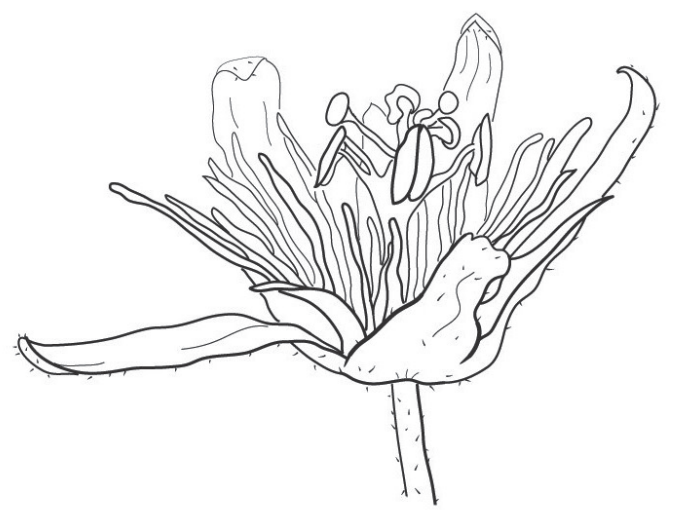

8.

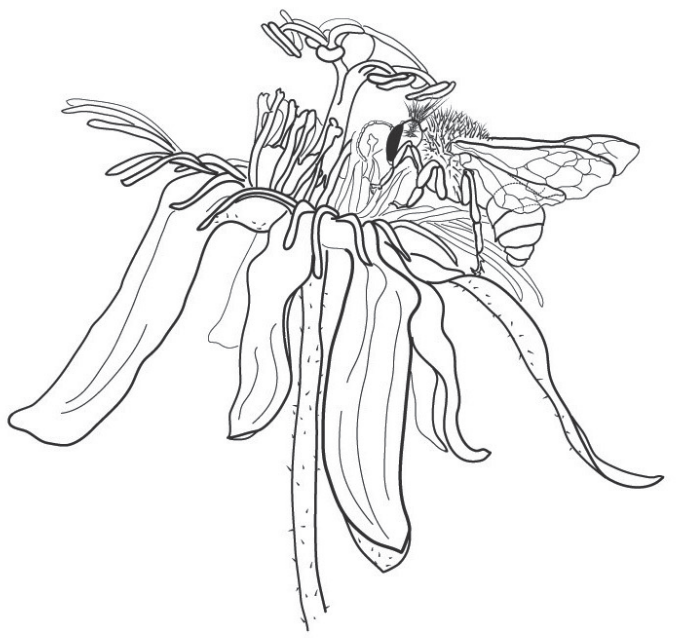

Figura 1-4. Passiflora capsularis. 1. Corte longitudinal da flor em antese (a-sépala, b-pétala, c-corona, d-opérculo, e-limen, f-androginóforo, g-filete, h-ovário, iestilete; seta-câmara nectarífera). 2. Flor em pré-antese. 3. Início da antese. 4. Flor ao final da antese. Figura 5-8. Passiflora pohlii. 5. Corte longitudinal da flor em antese (legenda idem Fig. 1). 6. Flor em pré-antese. 7. Flor se abrindo. 8. Flor ao final da antese sendo visitada por abelha do gênero Ptiloglossa, que é seu polinizador. 
Tabela 2. Visitantes florais, recursos procurados e atividades nas flores de Passiflora pohlii em Belo Horizonte, MG, Brasil.

\begin{tabular}{lll}
\hline Espécies & Recurso & Atividade \\
\hline Hymenoptera & & \\
Apidae & Néctar e pólen & Pilhador \\
$\quad$ Apis mellifera (Linnaeus, 1758) & Néctar e pólen & Pilhador \\
$\quad$ Trigona spinipes (Fabricius, 1793) & Néctar e pólen & Pilhador \\
$\quad$ Plebeia droryana (Friese, 1900) & & Néctar \\
Colletidae & Néctar & Polinizador \\
$\quad$ Ptiloglossa dubia (Moure, 1945) & Néctar & Polinizador \\
$\quad$ Ptiloglossa styphlaspis (Moure, 1945) & Néctar & Polinizador \\
Ptiloglossa latecalcarata (Moure, 1945) & & Pilhador \\
Formicidae não ident. & & Néctar \\
Diptera $\quad$ Drosophila melanogaster (Meigen, 1830) & & Pilhador \\
Droshilidae & & \\
\hline
\end{tabular}

ta) e quatro fêmeas não identificadas. As visitas iniciavam-se por volta das $5 \mathrm{~h}$ e após as $7 \mathrm{~h}$ estas abelhas eram raramente vistas visitando as flores. Pousavam nas flores sobre a corona circundando-as em sentido horário e anti-horário em busca de néctar, neste movimento, tocavam anteras e estigmas com o nototórax. Tanto machos quanto fêmeas visitaram as flores, mas as visitas das fêmeas ocorreram até as $6 \mathrm{~h}$ enquanto as dos machos até as $7 \mathrm{~h}$, com duração de 1 a 20 segundos. Eventualmente, foram encontrados machos nas flores até às $9 \mathrm{~h} 30 \mathrm{~min}$, os quais ficavam repousando sobre a corona. As espécies de Ptiloglossa podem ser consideradas os polinizadores da população de $P$. pohlii estudada.

Apis mellifera visitava as flores a partir de cerca de $8 \mathrm{~h}$ e eram restritas aos indivíduos maiores, portadores de muitas flores. Pousava sobre a corona e lambia o néctar. Seu pequeno tamanho não permitia contato com as partes reprodutivas das flores. Trigona spinipes foi observada coletando pólen e néctar. Estas abelhas pousavam sobre a corona e deslocavam-se em direção ao androginóforo, percorrendo os órgãos reprodutivos retirando quase todo o pólen das anteras. Para acessar o néctar, pousavam sobre a corona e ficavam entre os filamentos internos e o androginóforo. Enfiavam a língua entre as dobras do opérculo para lamber o néctar. Foram observados até três indivíduos numa mesma flor. As visitas iniciavam às $7 \mathrm{~h}$ e duravam em média 25 segundos, também se restringindo aos indivíduos maiores de $P$. pohlii. Tocavam os estigmas muito raramente, apenas quando passavam de uma antera para outra. Foram observadas raramente interações agonísticas entre os indivíduos de Trigona e de Ptiloglossa, que eram mordidos nas pernas. Nessas ocasiões, os indivíduos de Ptiloglossa abandonaram a flor. Plebeia droryana percorria as anteras coletando o pólen e armazenando-o nas corbículas. Assim como T. spinipes, tocavam os estigmas apenas na passagem de uma antera para outra, neste caso atuando como polinizadores eventuais.
Nas lâminas obtidas a partir de esfregaço de gelatina glicerinada no corpo dos visitantes, foi identificado pólen de P. pohlii no dorso do tórax e nas asas dos espécimes de Ptiloglossa e em todo o corpo de Apis, Trigona e Plebeia, principalmente nas corbículas. Em todos os indivíduos coletados, a ocorrência de pólen foi observada apenas de P. pohlii. As formigas caminhavam por toda a planta, utilizando principalmente os nectários extraflorais. Nas flores andavam sobre as pétalas e coronas em direção ao opérculo para tomar néctar. Não contatavam as partes reprodutivas. Drosophila melanogaster visitava as flores em busca de néctar. Eventualmente foram vistos casais em cópula sobre o androginóforo.

\section{Discussão}

Passiflora pohlii apresenta características morfológicas que a enquadram na síndrome de melitofilia, segundo Faegri \& van der Pijl (1980). Possui flores de tamanho médio, considerando os tamanhos observados no gênero Passiflora, com uma plataforma para visitantes, peças florais resistentes, odor agradável, néctar protegido e em quantidades moderadas. A série externa de filamentos da corona funciona como uma plataforma para as abelhas. Koschnitzke \& Sazima (1997) encontraram escamas de mariposas nos estigmas de $P$. capsularis e sugeriram que os prováveis polinizadores da espécie seriam deste grupo. Contudo, as características exibidas por $P$. capsularis, semelhantes àquelas encontradas em $P$. pohlii, permitem também enquadrá-la na síndrome de melitofilia. A antese noturna não é um empecilho para que os visitantes localizem as flores, que são encontradas pelos insetos pelo odor (Linsley 1958).

A duração das flores de ambas as espécies é de 8 a 12 horas e o tempo de deflexão do estilete é em torno de duas horas. Houve diferença na duração da antese da população de P. capsularis da RPPN do Caraça, quando comparada a uma 
população de São Paulo (Koschnitzke \& Sazima 1997). No Caraça, a antese iniciou por volta das $3 \mathrm{~h}$, enquanto que em São Paulo por volta das $00 \mathrm{~h} 30 \mathrm{~min}$. O início do fechamento das flores ocorria em São Paulo em torno das $11 \mathrm{~h}$ e o final às $13 \mathrm{~h}$, enquanto que no Caraça iniciava em torno das $11 \mathrm{~h}$ terminando por volta das $14 \mathrm{~h}$. Amela Garcia \& Hoc (1998a) também observaram diferenças no horário da antese de $P$. foetida, que foi anteriormente estuda por Janzen (1968) e atribuíram a isto diferenças nas condições de umidade e temperatura. Uma alternativa a ser considerada é a possibilidade da existência de distintos sistemas de polinização em P. capsularis, sendo as populações com flores de antese noturna (São Paulo) polinizadas por mariposas, como sugerido por Koschnitzke \& Sazima (1997), e as matutinas ou diurnas (Caraça) por abelhas. Os distintos padrões temporais de antese, neste caso, poderiam ser interpretados como uma resposta à divergência espacial dos polinizadores, que algumas vezes pode afetar as características morfológicas das flores (Herrera 1988; Herrera et al. 2006).

A concentração do néctar de $P$. pohlii (36\%) é característica das espécies melitófilas (Faegri \& van der Pijl 1980; Koschnitzke \& Sazima 1997; Amela Garcia \& Hoc 1998a; Varassin et al. 2001). Em P. capsularis, a concentração do néctar foi menor (22\%). Num estudo realizado com esta espécie no Parque Nacional do Iguaçu (Amela García 1999) também foram observados poucos visitantes florais, Augochloropsis sp. e Augochlorella sp., Lepidoptera, Diptera e Formicidae, classificados como pilhadores de néctar e pólen. A baixa freqüência de visitantes foi atribuída ao baixo número de indivíduos e à constante passagem de turistas no local, o que se assemelha às condições do local de ocorrência da população de $P$. capsularis estudada neste trabalho.

Os resultados dos tratamentos de polinização classificam $P$. pohlii como xenógama obrigatória. Essa espécie se mostrou autoincompatível ao contrário do esperado para espécies do gênero com flores pequenas e inconspícuas, como $P$. eglandulosa J. MacDougal (MacDougal 1988) e $P$. capsularis (Koschnitzke \& Sazima 1997). Amela Garcia \& Hoc (1999) também indicaram auto-incompatibilidade em $P$. misera. Entretanto, estas autoras apenas ensacaram botões a fim de verificar a autopolinização espontânea, e não fizeram testes de autopolinização manipulada, o que não permite definir seu sistema de incompatibilidade. No trabalho de Amela Garcia (1999), P. capsularis apresentou certo grau de autopolinização espontânea, visto que foi obtido $20 \%$ de frutos por este tratamento. Por outro lado, Koschnitzke \& Sazima (1997) não observaram produção de frutos com o mesmo tratamento, mas foram ensacadas apenas três flores. Os resultados dos tratamentos de polinização deste estudo classificam $P$. capsularis como autógama com sucesso da autopolinização espontânea de 14\%, que ocorre no momento da abertura da flor. Observou-se que o pólen desta espécie apresenta-se bastante pulverulento, sendo visto muitas vezes depositado secundariamente nos estiletes e estigmas das flores. A autopolinização espontânea em Passiflora é descrita para as espécies $P$. gracilis Jacq. ex Link, P. foetida L., P. helbertiana Lindl., P. morifolia Mast. e P. suberosa L. (Ulmer \& MacDougal 2004). A autofertilização e reprodução assexuada são características reprodutivas de espécies invasoras e pioneiras que ocupam clareiras e bordas de mata (Williamson 1996; Holsinger 2000), tais como as espécies de Passiflora. Durante eventos de invasão, as oportunidades de cruzamentos se reduzem e repetidos ciclos de colonização e baixa densidade podem favorecer tais tipos de reprodução para garantir a perpetuação da espécie (Barrett et al. 2007).

$\mathrm{O}$ retorno dos estiletes à posição inicial, quando a flor está se fechando, em $P$. capsularis foi registrado em $P$. alata, P. miersii (Koschnitzke \& Sazima 1997), P. caerulea (Amela Garcia \& Hoc 1997), P. foetida (Amela Garcia \& Hoc 1998a), P. moorana (Amela Garcia \& Hoc 1998b) e $P$. suberosa (Koschnitzke \& Sazima 1997; M.F. Acioli, com. pess.). Esse movimento do estilete parece não ter nenhuma relação com o sistema reprodutivo, uma vez que foi observado tanto em espécies autocompatíveis ( $P$. capsularis, $P$. suberosa; Koschnitzke \& Sazima 1997; P. foetida; Amela Garcia \& Hoc 1997) como em espécies autoincompatíveis ( $P$. alata, P. miersii; Koschnitzke \& Sazima 1997). A deflexão dos estiletes pode ter um significado ecológico, facilitando a polinização cruzada sendo esta característica retida nas espécies autocompatíveis. Nas espécies estudadas, esses movimentos não se relacionam com o período de receptividade estigmática, visto que mesmo na posição inflexa os estigmas já se apresentavam receptivos.

As espécies que polinizam P. pohlii são as abelhas do gênero Ptiloglossa. Polinizadores deste gênero já foram descritos para as espécies P. foetida (Janzen 1968; Amela Garcia \& Hoc 1998a), P. misera e P. chrysophylla Chodatt (Amela Garcia \& Hoc 1999). Passiflora mooreana também foi visitada por Ptiloglossa, entretanto a freqüência desta abelha foi muito baixa, não sendo considerada um polinizador importante (Amela Garcia \& Hoc 1998b). As espécies de Passiflora polinizadas por estas abelhas possuem flores pequenas, com antese no início da manhã. O período de antese destas espécies coincide com o período do dia em que estas abelhas estão ativas e, segundo Linsley (1958), estas abelhas localizam seu recurso pelo odor. Além disso, a concentração do néctar nestas flores varia de $29 \%$ a $34 \%$ (Amela Garcia \& Hoc 1999), valores próximos à concentração do néctar de P. pohlii (36\%).

As espécies de Ptiloglossa são abelhas solitárias, cujas fêmeas da maioria das espécies têm hábitos crepusculares e os machos podem ser encontrados principalmente durante a manhã (Silveira et al. 2002). Segundo Janzen (1968), essas abelhas voam durante uma hora antes do amanhecer e até duas horas após o pôr do sol e ocasionalmente durante a noite. As abelhas Ptiloglossa polinizadoras de Passiflora pohlii parecem ser primariamente matutinas (Linsley \& Cazier 1970), pois nos indivíduos coletados foi encontrado apenas o pólen de P. pohlii, cuja antese é coincidente com a atividade da abelha. Entretanto, como não foram feitas 
observações no ninho nem coletas noturnas destas abelhas, não podemos afirmar se tais espécies são ativas apenas na parte da manhã. Linsley \& Cazier (1970), estudando $P$. arizonensis e $P$. jonesi, verificaram que a atividade matinal destas abelhas inclui mais viagens em busca de néctar do que pólen. Este fato pode ser corroborado com os dados obtidos das fêmeas de Ptiloglossa visitantes de P. pohlii, que foram encontradas sem nenhum pólen nas escopas, mas concentrado no nototórax e utilizaram esta espécie como fonte de néctar. A provisão do ninho dessas abelhas é uma mistura líquida contendo mais néctar do que pólen (Roberts 1971). Não foi possível assegurar se o comportamento observado no qual um indivíduo de Ptiloglossa agarrava o outro seria um comportamento de cópula ou defesa de território pelos machos. Segundo Linsley (1958), a cópula é muito breve e difícil de observar, durando poucos segundos e pode ocorrer no entorno do ninho ou nas flores visitadas pelas fêmeas. Além disso, Linsley \& Cazier (1970) e Roberts (1971) descrevem territorialismo entre os machos próximos aos ninhos e flores.

Linsley (1958) considera a grande maioria das abelhas solitárias como oligoléticas (utilizam como recurso poucas espécies de plantas) ou monoléticas (tem como fonte de recurso uma única espécie de planta), mas as espécies estudadas por Linsley \& Cazier (1970) foram classificadas como poliléticas. A interação entre a população estudada de P. pohlii e as abelhas do gênero Ptiloglossa parece ser um caso de especialização visto que em todos os exemplares coletados (24 machos e quatro fêmeas) foi encontrado apenas pólen de $P$. pohlii. Isto sugere que $P$. pohlii é uma espécie monofílica (Faegri \& van der Pilj 1980), sendo polinizada apenas por uma única espécie ou espécies intimamente relacionadas do gênero Ptiloglossa. Esta interação é de fundamental importância para $P$. pohlii, visto que esta espécie é auto-incompatível e depende do polinizador para a sua reprodução sexuada.

As abelhas $A$. mellifera, $P$. droryana e $T$. spinipes foram freqüentes nos indivíduos maiores e com muitas flores. Nos indivíduos menores, apenas as abelhas Ptiloglossa foram observadas. Trigona spinipes parece não causar nenhum prejuízo à $P$. pohlii, ao contrário do que foi observado para $P$. coccinea (Boiça Júnior et al. 2004) e para $P$. edulis (Sazima \& Sazima 1989), visto que em $P$. pohlii estas abelhas pilhadoras raramente forrageavam no mesmo período em que as abelhas Ptiloglossa, ou seja suas atividades de visita começavam quando os polinizadores já tinham visitado as flores. Esta parece ser uma estratégia bastante eficaz de visitantes noturnos por diminuir a competição interespecífica (Wcislo et al. 2004).

Os estudos de biologia reprodutiva com as espécies $P$. capsularis e $P$. pohlii, bem como outras espécies do subgênero Decaloba, indicam que sistemas de polinização distintos em comparação com o subgênero Passiflora. Enquanto neste último subgênero houve uma radiação adaptativa para a polinização por abelhas, aves e morcegos, no subgênero
Decaloba predomina a polinização por himenópteros, principalmente abelhas do gênero Ptiloglossa. Embora poucas espécies tenham sido estudadas, a antese noturna encontrada nas espécies de Passiflora sugere haver uma relação evolutiva entre espécies de Passiflora subg. Decaloba e himenópteros com hábito noturno, especialmente abelhas do gênero Ptiloglossa.

\section{Agradecimentos}

Ao Prof. Dr. Fernando A. Silveira, da Universidade Federal de Minas Gerais (UFMG), pela determinação das abelhas; Fernando A. O. Silveira pelo auxílio na estatística; RPPN do Caraça pela hospedagem dos pesquisadores; Capes pela bolsa de Mestrado do primeiro autor e aos assessores anônimos pelas valiosas sugestões ao manuscrito.

\section{Referências bibliográficas}

Amela Garcia, M.T. \& Hoc, P. 1997. Floral biology and reproductive system of Passiflora caerulea (Passifloraceae). Beiträge zur Biologie der Pflanzen 70: 1-20.

Amela Garcia, M.T. \& Hoc, P. 1998a. Biología floral de Passiflora foetida (Passifloraceae). Revista de Biología Tropical 46: 1-11.

Amela Garcia, M.T \& Hoc, P. 1998b. Aspectos de la biología floral y el sistema reproductivo de Passiflora mooreana (Passifloraceae). Darwiniana 35: 9-27.

Amela Garcia, M. T. 1999. Biología floral y sistema reproductivo de especies nativas de Passiflora (Passifloraceae) de la Argentina. Tese de doutorado. Universidad de Buenos Aires, 286 p.

Amela Garcia, M.T. \& Hoc, P.S. 1999. Pollination of Passiflora: do different pollinators serve species belonging to different subgenera? Acta Horticulturae 561: 71-74.

Antunes, F.Z. 1986. Caracterização climática do estado de Minas Gerais. Informe Agropecuário 12: 9-13.

Barrett, S.C.H.; Colautti, R.I . \& Eckert, C.G. 2008. Plant reproductive systems and evolution during biological invasion. Molecular Ecology 17: $373-383$.

Boiça Júnior, A.L.; Santos, T. M. \& Passilongo, J. 2004. Trigona spinipes (Fabr.) (Hymenoptera: Apidae) em espécies de maracujazeiro: Flutuação populacional, horário de visitação e danos às flores. Neotropical Entomology 33: 135-139.

Buzato, S. \& Franco, A.L.M. 1992. Tetrastylis ovalis: a second case of bat-pollinated passionflower (Passifloraceae). Plant Systematics and Evolution 181: 261-267.

Cervi, A.C. 2005. Espécies de Passiflora L. (Passifloraceae) publicadas e descritas nos últimos 55 anos (1950-2005) na América do Sul e principais publicações brasileiras. Estudos de Biologia 27: 19-24.

Dafni, A. 1992. Pollination ecology. A practical approach. Oxford. Oxford University Press.

Endress, P.K. 1994. Diversity and evolutionary biology of tropical flowers. Cambridge, Cambridge University Press,

Faegri, K. \& van der Pijl, L. 1980. The principles of pollination ecology. New York, Pergamon Press.

Feuillet, C. \& MacDougal, J. 2003. A new infrageneric classification of Passiflora L. (Passifloraceae). Passiflora 12: 34-38.

Heywood, V.H. 1993. Flowering plants of the world. New York, Oxford University Press.

Herrera, C. M. 1988. Variation in mutualisms: the spatiotemporal mosaic of a pollinator assemblage. Biological Journal of the Linnean Society 35: $95-125$.

Herrera, C. M.; Castellanos, M. C. \& Medrano, M. 2006. Geographical context of floral evolution: towards an improved research programme in floral diversification. In: L.D. Harder \& S.C.H. Barrett (eds). Ecology and evolution of flowers. Oxford, Oxford University Press.

Holsinger, K.E. 2000. Reproductive systems and evolution in vascular plants. Proceedings of the National Academy of Sciences, USA 97: 7037-7042.

Janzen, D.H. 1968. Reproductive behaviour in the Passifloraceae and some of its pollinators in Central America. Behavior 32: 33-48. 
Kearns, C.A. \& Inouye, D.W. 1955. Techniques for pollination biologists Niwot, University Press of Colorado.

Killip, E.P. 1938. The American species of Passifloraceae. Botanical Series Volume XIX. Chicago, Field Museum of Natural History.

Koschnitzke, C. \& Sazima, M. 1997. Biologia floral de cinco espécies de Passiflora L. (Passifloraceae) em mata semidecídua. Revista Brasileira de Botânica 20: 119-126.

Linsley, E. G. 1958. The ecology of solitary bees. Hilgardia 27: 543-599.

Linsley, E.G. \& Cazier, M.A. 1970. Some competitive relationships among matinal and late afternoon foraging activities of Capolicanine bees in southeastern Arizona (Hynmenoptera, Colletidae). Journal of the Kansas Entomological Society 43: 251-261.

MacDougal, J.M. 1988. Passiflora eglandulosa, a new species in section Cieca (Medikus) DC. formely included with P. trinifolia Masters. Annals of the Missouri Botanical Garden 75: 1658-1662.

MacDougal, J.M. 1994. Revision of Passiflora subgenus Decaloba section Pseudodysosmia (Passifloraceae). Systematic Botany Monographs 41: $1-146$.

Manica, I. 1981. Fruticultura tropical: Maracujá. São Paulo. Editora Agronômica Ceres.

May, P.G. \& Spears Junior, E.E. 1988. Andromonoecy and variation in phenotypic gender of Passiflora incarnata (Passifloraceae). American Journal of Botany 75: 1830-1841.

Milward-de-Azevedo, M.A. \& Baumgratz, J.F.A. 2004. Passiflora L. subgênero Decaloba (DC.) Rchb. (Passifloraceae) na região Sudeste do Brasil. Rodriguésia 55: 17-54.

Muschner, V.C.; Lorenz, A.P.; Cervi, A.C.; Bonatto, S.L.; Souza-Chies, T.T.; Salzano, F.M. \& Freitas, L.B. 2003. A first molecular phylogenetic analysis of Passiflora (Passifloraceae). American Journal of Botany 90: $1229-1238$.

Nunes, T.S. \& Queiroz, L.P. 2001. A família Passifloraceae na Chapada Diamantina, Bahia, Brasil. Sitientibus, Série Ciências Biológicas 1: 33-46.

Radford, A.E.; Dickson, W.C.; Massey, J.R. \& Bell, C.R. 1974. Vascular plant systematics. New York, Harper \& Row Publischers.
Roberts, R. B. 1971. Biology of the crepuscular bee Ptiloglossa guinnae n.sp. with notes on associated bees, mites and yeasts. Journal of the Kansas Entomological Society 44: 283-294.

Robinsohn, I. 1924. Die farbungsreaktion der narbe, stgmatochromie, als morphobiologische Blütenuntersuchungsmethode. Sitzungsberichten Akademischer Wissenschaft Wien, Mathematics Abteilung 133: 180-213.

Sacco, J.C. 1980. Flora ilustrada catarinense. Passifloraceae. Itajaí. Herbário Barbosa Rodrigues.

Santos, P K.; Lemke, A.P.L.; Muschner, V.C.; Bonatto, S. L.; Salzano, F.M.; \& Freitas L.B. 2006. Molecular genetic variation in Passiflora alata, an invasive species in Southern Brazil. Biological Journal of the Linnean Society 88: 611-630.

Sazima, M. \& Sazima, I. 1978. Bat pollination of the passion flower, Passiflora mucronata, in southeastern Brazil. Biotropica 10: 100-109.

Sazima, I. \& Sazima, M. 1989. Mamangavas e irapuás (Hymenoptera, Apoidea): visitas, interações e conseqüências para polinização do maracujá (Passifloraceae). Revista Brasileira de Entomologia 33: 109-118.

Silveira, F.A.; Melo, G.A.R. \& Almeida, E.A.B. 2002. Abelhas brasileiras: sistemática e identificação. Belo Horizonte, Ministério do Meio Ambiente, Fundação Araucária.

Snow, A.A. 1982. Pollination intensity and potencial seed set in Passiflora vitifolia. Oecologia 55: 231-237.

Ulmer, T. \& MacDougal, J.M. 2004. Passiflora. Passionflowers of the world. Portland. Timber Press.

Varassin, I. G. \& Silva, A.G. 1999. A melitofilia em Passiflora alata Dryander (Passifloraceae), em vegetação de restinga. Rodriguésia 50: 5-17.

Varassin, I.G.; Trigo, J.R. \& Sazima, M. 2001. The role of nectar production, flower pigments and odour in the pollination of four species of Passiflora (Passifloraceae) in south-eastern Brazil. Botanical Journal of the Linnean Society 136: 139-152.

Wcislo, W.T.; Arneson, L.; Roesch, K.; Gonzalez, V.; Smith, A. \& Fernandez, H. 2004. The evolution of nocturnal behavior in sweat bees, Megalopta genalis and M. ecuadoriana (Hymenoptera: Halictidae): an escape from competitors and enemies? Biological Journal of the Linnean Society 83: 377-387.

Williamson, M. 1996. Biological invasions. London. Chapman \& Hall. 